\title{
A CASE OF SECONDARY HAEMORRHAGE FOLLOWING CURETTAGE OF MEIBOMIAN CYST
}

\author{
BY
}

\author{
J. G. D. CURRIE and J. P. F. Lloyd
}

CHELTENHAM

WE believe this case to be worth reporting owing to the extreme rarity of the emergency which arose. We can find only one reference to such an occurrence, this being, unfortunately unobtainable in this country : ${ }^{1}$ and on enquiry at Moorfields the condition was apparently unheard of except for one instance. We shall refer to this in the course of the report.

The patient was an American girl, aged 23 years who was touring England for her health after a 'nervous breakdown.' She consulted Mr. J. G. D. Currie, in August last year for what amounted literally to a crop of Meibomian cysts, nine of them distributed over the four eyelids. She gave a history of having had one similar cyst curetted in America in the right lower lid.

She refused any form of procedure under local anaesthesia and consequently, rather against his wishes, Mr. Currie consentee to curette them all at one sitting under general anaesthesia.

This was on August 3. Recovery from the anaesthetic was uneventful : reaction in the lids was trifling, and all the cysts appeared to be following the normal course of healing by second intention.

On August 7 at 3 a.m. her parents telephoned to the effect that there was some bleeding from the right eye; the magnitude of this not being considered serious she was advised to try pressure on the lids for a time. An hour later she was brought to our consulting rooms with two face towels wrapped round her head, both copiously soaked in blood.

On examination there was seen a definite spurting artery. All attempts to arrest this on the spot failed; mainly owing to the patient's great sensitivity and nervousness.

She was removed to a nursing home forthwith. Here, after $\frac{7}{2}$ injecting a little novocaine-adrenalin, it was found possible to get a satisfactory view of the lid. The offending cyst was in the $\stackrel{N}{\sigma}$ centre of the right lower lid, gaping open with sloughy-looking $N$ edges, and filled with blood clot. There was now no haemorrhage at all.

An 000 silk suture was passed twice right through the thickness of the lid, just to the basal side of the cyst, and tied over a small rubber tube on the skin. 
There was no further haemorrhage, and the patient was returned to bed. She was somewhat blanched, but the pulse rate was 80 only and of good volume.

It was now discovered that the patient had been suffering from whooping cough for a few days, and it was thought that this might have been an exciting cause of the haemorrhage. It was also mentioned by the parents at this stage that the cyst from which the haemorrhage had occurred, corresponded in site to the one which had been previously curetted.

For forty-eight hours all went well, the suture being well tolerated, with very little local reaction or swelling. The whooping cough was only moderately controlled by sedatives.

Forty-eight hours after the first suture profuse haemorrhage commenced again. It was practically uncontrolled by adrenalin pack and pressure dressing, rapidly soaking through the latter. A complete blood investigation showed no trace of any abnormality, apart from slight anaemia of secondary type. The liver and spleen were of normal size and coagulation and bleeding times were normal.

The patient was given a general anaesthetic, with a view to more extensive suture. On arrival on the table the bleeding had ceased, and did not re-start on taking out the previous suture. Three 000 silk sutures were passed right round the cyst and tied firmly. The patient was kept on the table for an hour, but no further bleeding was observed. Her pulse was 90 .

There was no further bleeding and the sutures were removed on the fifth day. At this time the lid was still rather swollen and discoloured, and an acute Meibomian abcess of the small marginal type was found just external to the haemorrhagic one.

This was squeezed out and the whole lid was rapidly approaching normal when we last saw her three weeks after the first haemorrhage, when she was about to make the journey home.

\section{Comment}

As mentioned at the start, we believe this condition to be extremely rare, though we can see no reason why secondary haemorrhage is unusual as a sequel of the procedure, as the requisite infective process is present in the cyst, and also frequently in the conjunctival sac.

The first suture was presumably ineffective after a time, as, being two to three $\mathrm{mm}$. away from the bleeding point, it failed to compress the vessel as the local swelling subsided.

An alternative method suggested by Mr. A. H. Briggs ${ }^{2}$ and used by him in his recent case, would have been to suture the palpebral conjunctiva tightly over the cyst. This was success- 
ful, but resulted in extensive ecchymosis. Perhaps the most certain method of arresting such a haemorrhage is that adopted by the writer, namely, the passing of a suture round the cyst itself ; certainly no ill effect was observed from this.

Finally, it is interesting to speculate as to how far the presence of pertussis was a contributory factor.

REFERENCES

1. Rowland, W. P.-Jl. Ophthal. Otol. and Laryng., Vol. XXXIII, pp. 177-180, 1929.

2. Briggs, A. H.-Personal communication.

\section{A CASE OF ACUTE UNILATERAL RETRO-BULBAR NEURITIS ASSOCIATED WITH NASAL-SINUS DISEASE}

BY

R. R. James, Sir StClair Thomson, Lionel Colledge and H. Graham Hodgson, C.V.O.

LONDON

\section{Introduction. (R.R.J.)}

RETRO-BULbar neuritis, due to nasal sinusitis, is probably much less common than was formerly thought. It is true that a retrobulbar neuritis may occasionally be due to absorption from some septic focus. I have seen such a case in a patient with severe dental sepsis. The eye. condition ran an acute course, was bilateral and cleared up completely in about four months' time.

In my early days at St. George's Hospital I saw a chronic type of case. Mr. Harold Barwell found evidence of nasal sinus trouble; the man was operated on and went out with much improved vision. A few years later the condition recurred and the patient was sent to Mr. J. B. Lawford who wrote to me for the n'tes of the case. In writing to thank me for them Mr. Lawford told me that, on reviewing the case, he had come to' the conclusion that the ocular condition was entirely due to tobacco!

The case which we now report would seem to be of some rarity.

\section{The Nasal History. (SIR STC. T.)}

The patient first came under observation in 1930 with evidence of suppuration in the left maxillary sinus. He was then 72 years of age and, being averse from a larger operation, the sinus was simply drained through an opening in an empty molar socket. 